\title{
Assessment of perceived health status among primary care patients in Southern Italy: findings from a cross-sectional survey
}

\author{
Benedetto Manuti, Paolo Rizza, Claudia Pileggi, Aida Bianco and Maria Pavia*
}

\begin{abstract}
Background: The primary aim of this study was to measure HRQOL of primary care patients in one of the poorest areas of Italy, using SF-12, whereas the secondary aim was to identify subgroups of this population, according to socio-demographics, clinical characteristics, behavioural risk factors, and health services utilization, that manifest poorer HRQOL. These data may be helpful to policy makers to implement health care policies and social interventions for improving HRQOL.

Methods: A cross-sectional survey was conducted in Southern Italy on primary care patients aged 18 and over. SF-12 was used to measure perceived health status. Physical component and mental summary scores were obtained. We performed univariate and multivariate analysis to evaluate eventual significant differences of mean PCS-12 and MCS-12 according to various characteristics (demographics, presence of chronic diseases, behavioral risk factors, and utilization of health services).

Results: Of the 1467 participating in our survey, more than one third evaluated their health as unsatisfactory, noted significant limitations and reported problems on all SF-12-scales. Physical and mental summary scores showed an overall mean of 45.9 (SD \pm 10.8 ) and 44.9 (SD \pm 11.6 ), respectively. Statistical analysis showed significant differences in perceived health status by socio-demographic characteristics, such as gender, age, education level and employment status, by behavioral risk factors, chronic diseases and health services utilization.

Conclusions: Our findings seem to indicate that primary care patients in Southern Italy have a poor HRQOL and this perception is even poorer in subgroups of the population, according to several sociodemographic, clinical characteristics, and behavioural risk factors. These results may have significant implications for health care policymakers, since they emphasize the need of developing effective and targeted strategies to improve HRQOL in Southern Italy.
\end{abstract}

Keywords: Quality of life, Mental health, Physical function, Health policy

\section{Background}

Attention to perceived health status or "health related quality of life" (HRQOL) assessment has been increasing, since it represents an important component and one of the most effective strategies to evaluate quality of life, a multidimensional construct comprising physical, mental, social and economic components [1].

Many instruments are currently available to measure HRQOL, and Short-Form-12 Health Survey (SF-12) [2],

\footnotetext{
* Correspondence: pavia@unicz.t

Department of Health Sciences, Medical School, University of Catanzaro "Magna Græcia", Catanzaro, Italy
}

is the most commonly used one. SF-12 is a short form health survey, developed as an alternative to the SF-36 [3]. SF-12 has been adopted by numerous health care delivery organizations, including the National Commission on Quality Assurance, and has been successfully tested in several countries, including Italy [4-7]. It has been extensively used in studies involving the general population $[5,8,9]$, as well as vulnerable populations, such as elderly, minority subjects and patients with common diseases [10-14].

Several studies have focused on the distribution of socio-demographics, clinical characteristics, behavioural 
risk factors, and health services utilization according to physical and mental perceived health status, and have found significant differences associated with patients' characteristics, such as gender, age, education level, social relationships, presence of medical problems, race or ethnic group, socio-economic and employment status [8,9,15-20].

During the 1990s Italy promoted political and financial regional decentralization, the consequence of which resulted in dramatic new responsibilities for regulating, planning and organizing health care delivery that has been transferred to the regions. The process of decentralization certainly represents progress but may increase risk of reducing HRQOL in poorer regions of South. Therefore, it is crucial to have regional disaggregated data on HRQOL, to identify possible differences among regions and with other countries and to assess the relationships between subjects' characteristics and HRQOL to understand how policy makers can face deregulation and improve strategies to reach disadvantaged groups.

In Italy, all residents are provided a primary care physician (PCP) within the National Health Service, who acts as a "gate keeper" to preventive, diagnostic, therapeutic and rehabilitative services. Therefore, subjects attending PCPs certainly represent a subgroup of individuals seeking a health demand, and consequently of great interest in the assessment of HRQOL.

The primary aim of this study was to measure HRQOL of primary care patients in one of the poorest areas of Italy, using SF-12, whereas the secondary aim was to identify subgroups of this population, according to socio-demographics, clinical characteristics, behavioural risk factors, and health services utilization, that manifest poorer HRQOL. These data may be helpful to policy makers to implement health care policies and social interventions for improving HRQOL.

\section{Methods}

\section{Study population and sample size}

This cross sectional study was carried out in Calabria Region (Southern Italy), having a population of approximately 2 million living in 3 major cities and several smaller centers. About 1500 PCPs provide primary care to 1.6 million of patients (adults aged 18 years and over).

To enable the sample to better represent the patients characteristics, a multi-stage sampling was performed. First, we selected two cities having urban and demographic characteristics typical of the Southern part of the country; the former (Catanzaro) is the capital of the region and have 60 PCPs with 77,022 primary care patients; the latter (Crotone) is a small town with 38 PCPs (44,047 primary care patients). Then, we proportionally selected by simple random sampling 20 PCPs from the lists provided by the Local Health Units: 12 from Catanzaro and 8 from Crotone.

All consecutive subjects attending PCP for non urgent issues were recruited. Anonymous questionnaires, pretested on a sample of patients to ensure clarity of interpretation and ease of completion, were administered before the consultation with the PCP, by two trained physicians, to all patients agreeing to participate. Of the original sample of 1716 subjects, 1467 agreed to participate (85.5\% response rate). Verbal informed consent was obtained from the participants for publication of this research. All information was self-reported by the participants. No medical records or interviews by any PCPs were used as sources of data.

\section{Review instrument}

We used SF-12 [2], in its validated Italian version [21], to measure HRQOL.

The eight health domains assessed by the SF-12 may be aggregated into two summary measures, the Physical Component Summary (PCS-12) and the Mental Component Summary (MCS-12), applying a scoring algorithm empirically derived from the data of a US general population survey [22]. As recommended, we have standardized our scores according to US norm data (mean score $=50 ; \mathrm{SD}=10$ ), in order to facilitate cross-cultural comparison of results [6].

Chronic diseases were defined as one or more selfreported diagnoses for diseases of long duration and generally slow progression, such as hypertension, heart disease, diabetes, stroke, cancer, psychiatric disorders, osteoarthritis, respiratory diseases, etc. [23].

To assess smoking and alcohol consumption habits we used the questions and the definitions of current smoking, current and heavy drinking derived from the Behavioral Risk Factor Surveillance System questionnaire 2007 [24]. This questionnaire is currently adopted in a surveillance system on major behavioral risk factors in the Italian general population [25]. Excessive alcohol use, according to International Drinking Guidelines [26], was defined on the basis of either heavy drinking, binge drinking, or both.

Moreover, the questionnaire included information on patient's socio-demographic characteristics and utilization of health services during the previous year, including information on number and main reasons for specialist visit, emergency access, and hospital admission.

The study protocol was approved by Ethics Committee of the "Mater Domini" Hospital of Catanzaro (Italy) (Prot. E.C. n. 127/2006).

\section{Statistical analysis}

We performed univariate [ $\mathrm{t}$-Test and analysis of variance (ANOVA)] and multivariate (stepwise multiple linear regression) analysis to evaluate eventual significant 
Table 1 SF-12 summary scores according to selected characteristics of the study population

\begin{tabular}{|c|c|c|c|}
\hline Characteristics & $\mathrm{N}(\%)$ & PCS-12 Mean $( \pm S D)$ & MCS-12 Mean ( \pm SD) \\
\hline \multicolumn{4}{|l|}{ Socio-demographic profile } \\
\hline \multicolumn{4}{|l|}{ Sex } \\
\hline Male & $660(45)$ & $46.8( \pm 10.4)$ & $47.7( \pm 10.8)$ \\
\hline \multirow[t]{2}{*}{ Female } & $807(55)$ & $45.1( \pm 11.7)$ & $42.6( \pm 11.7)$ \\
\hline & & t-test $(1465)=3.01, p=0.003$ & t-test $(1465)=8.45, p<0.001$ \\
\hline \multicolumn{4}{|l|}{ Age group, years } \\
\hline $18-45$ & $498(33.9)$ & $51.4( \pm 7.7)$ & $46.3( \pm 11.4)$ \\
\hline $46-64$ & $541(36.9)$ & $46.5( \pm 10)$ & $44.9( \pm 11.6)$ \\
\hline \multirow[t]{2}{*}{$\geq 65$} & $428(29.2)$ & $38.6( \pm 10.6)$ & $43.2( \pm 11.7)$ \\
\hline & & F-test $(2,1464)=214.95, p<0.001$ & F-test $(2,1464)=8.17, p<0.001$ \\
\hline \multicolumn{4}{|l|}{ Marital status } \\
\hline Married & $988(67.3)$ & $45.2( \pm 10.5)$ & $45.2( \pm 11.5)$ \\
\hline \multirow[t]{2}{*}{ Other } & $479(32.7)$ & $47.2( \pm 11.1)$ & $44.2( \pm 11.8)$ \\
\hline & & t-test $(1465)=-3.34, p<0.001$ & t-test $(1465)=1.50, p=0.13$ \\
\hline \multicolumn{4}{|c|}{ Additional persons in the household } \\
\hline None & $138(9.4)$ & $41.4( \pm 11.7)$ & $43.5( \pm 11.2)$ \\
\hline 1 & $384(26.2)$ & $42.5( \pm 11.2)$ & $44.3( \pm 12.2)$ \\
\hline \multirow[t]{2}{*}{$>1$} & $945(64.4)$ & $47.9( \pm 9.9)$ & $45.3( \pm 11.4)$ \\
\hline & & F-test $(2,1464)=50.99, p<0.001$ & F-test $(2,1464)=2.23, p=0.11$ \\
\hline \multicolumn{4}{|l|}{ Education level } \\
\hline No formal education & $305(20.8)$ & $38.6( \pm 11.3)$ & $42.9( \pm 12.6)$ \\
\hline Primary school & $309(21)$ & $43.4( \pm 10.5)$ & $44( \pm 11.7)$ \\
\hline Secondary school & $588(40.1)$ & $49.2( \pm 9.1)$ & $44.7( \pm 11.4)$ \\
\hline \multirow[t]{2}{*}{ University degree } & $265(18.1)$ & $49.8( \pm 8.5)$ & $48.7( \pm 9.7)$ \\
\hline & & F-test $(3,1463)=98.30, p<0.001$ & F-test $(3,1463)=13.49, p<0.001$ \\
\hline \multicolumn{4}{|l|}{ Working activity } \\
\hline No & $843(57.5)$ & $43.4( \pm 11.4)$ & $43.6( \pm 12)$ \\
\hline \multirow[t]{2}{*}{ Yes } & $624(42.5)$ & $49.2( \pm 8.7)$ & $46.6( \pm 10.9)$ \\
\hline & & t-test $(1465)=-10.62, p<0.001$ & t-test $(1465)=-4.80, p<0.001$ \\
\hline \multicolumn{4}{|c|}{ Utilization of health services during the previous year } \\
\hline \multicolumn{4}{|l|}{ PCP accesses } \\
\hline$<12$ & $782(53.3)$ & $49.8( \pm 9)$ & $47( \pm 11)$ \\
\hline \multirow[t]{2}{*}{$\geq 12$} & $685(46.7)$ & $41.4( \pm 10.8)$ & $42.5( \pm 11.9)$ \\
\hline & & t-test $(1465)=16.33, p<0.001$ & t-test $(1465)=7.52, p<0.001$ \\
\hline \multicolumn{4}{|l|}{ PCP medical visits } \\
\hline None & $528(36)$ & $49.8( \pm 9.2)$ & $47.3( \pm 11.4)$ \\
\hline$<12$ & $590(40.2)$ & $46.5( \pm 10.3)$ & $44.4( \pm 11.3)$ \\
\hline \multirow[t]{2}{*}{$\geq 12$} & $349(23.8)$ & $38.9( \pm 10.4)$ & $42.2( \pm 11.8)$ \\
\hline & & F-test $(2,1464)=129.14, p<0.001$ & F-test $(2,1464)=21.99, p<0.001$ \\
\hline \multicolumn{4}{|c|}{ Specialist visits in community health services } \\
\hline None & $890(60.7)$ & $47.9( \pm 10.2)$ & $46.1( \pm 11.5)$ \\
\hline \multirow[t]{2}{*}{$\geq 1$} & $577(39.3)$ & $42.7( \pm 10.8)$ & $43.1( \pm 11.5)$ \\
\hline & & t-test $(1465)=9.43, p<0.001$ & t-test $(1465)=4.89, p<0.001$ \\
\hline
\end{tabular}


Table 1 SF-12 summary scores according to selected characteristics of the study population (Continued)

\begin{tabular}{|c|c|c|c|}
\hline \multicolumn{4}{|c|}{ Private specialists visits } \\
\hline None & $778(53)$ & $45.7( \pm 11)$ & $45.6( \pm 11.5)$ \\
\hline \multirow[t]{2}{*}{$\geq 1$} & $689(47)$ & $46.1( \pm 10.5)$ & $44.1( \pm 11.5)$ \\
\hline & & t-test $(1465)=-0.68, p=0.50$ & t-test $(1465)=2.55, p=0.011$ \\
\hline \multicolumn{4}{|c|}{ Emergency accesses } \\
\hline None & $1129(77)$ & $46.5( \pm 10.6)$ & $45.4( \pm 11.4)$ \\
\hline \multirow[t]{2}{*}{$\geq 1$} & $338(23)$ & $43.7( \pm 10.9)$ & $43.2( \pm 12.1)$ \\
\hline & & t-test $(1465)=4.28, p<0.001$ & t-test $(1465)=3.11, p=0.002$ \\
\hline \multicolumn{4}{|c|}{ Hospital admissions } \\
\hline None & $1279(87.2)$ & $46.7( \pm 10.4)$ & $45.3( \pm 11.6)$ \\
\hline \multirow[t]{2}{*}{$\geq 1$} & $188(12.8)$ & $40.6( \pm 11.4)$ & $42.1( \pm 11.5)$ \\
\hline & & t-test $(1465)=7.38, p<0.001$ & t-test $(1465)=3.54, p<0.001$ \\
\hline \multicolumn{4}{|c|}{ Behavioral risk factors and medical conditions } \\
\hline \multicolumn{4}{|l|}{ Smoking habit } \\
\hline Never smoker & $724(49.3)$ & $45.1( \pm 11.1)$ & $44.6( \pm 12)$ \\
\hline Ex-smoker & $360(24.6)$ & $44.2( \pm 10.5)$ & $45.9( \pm 10.4)$ \\
\hline \multirow[t]{2}{*}{ Current smoker } & $383(26.1)$ & $49( \pm 9.6)$ & $44.6( \pm 12)$ \\
\hline & & F-test $(2,1464)=10.03, p=0.007$ & F-test $(2,1464)=1.82, p=0.162$ \\
\hline \multicolumn{4}{|c|}{ Excessive alcohol use } \\
\hline No & $1346(91.7)$ & $45.7( \pm 10.7)$ & $44.7( \pm 11.7)$ \\
\hline \multirow[t]{2}{*}{ Yes } & $121(8.3)$ & $47.9( \pm 10.8)$ & $47.3( \pm 10.8)$ \\
\hline & & t-test $(1465)=-2.13, p=0.033$ & t-test $(1465)=-2.41, p=0.016$ \\
\hline \multicolumn{4}{|l|}{ Chronic diseases } \\
\hline 0 & $569(38.8)$ & $52.3( \pm 6.9)$ & $47.9( \pm 10.7)$ \\
\hline 1 & $478(32.6)$ & $45.3( \pm 10)$ & $44.8( \pm 11.4)$ \\
\hline 2 & $270(18.4)$ & $39.5( \pm 10.2)$ & $41.4( \pm 12)$ \\
\hline \multirow[t]{2}{*}{$\geq 3$} & $150(10.2)$ & $34.9( \pm 9.7)$ & $40.1( \pm 11.6)$ \\
\hline & & F-test $(3,1463)=219.38, p<0.001$ & F-test $(3,1463)=31.17, p<0.001$ \\
\hline \multicolumn{4}{|l|}{ Hypertension } \\
\hline No & $973(66.3)$ & $48.4( \pm 9.9)$ & $46.1( \pm 11.5)$ \\
\hline \multirow[t]{2}{*}{ Yes } & $494(33.7)$ & $40.9( \pm 10.6)$ & $42.5( \pm 11.6)$ \\
\hline & & t-test $(1465)=13.4, p<0.001$ & t-test $(1465)=5.57, p<0.001$ \\
\hline \multicolumn{4}{|l|}{ Diabetes } \\
\hline No & $1300(88.6)$ & $46.7( \pm 10.5)$ & $45.1( \pm 11.6)$ \\
\hline \multirow[t]{2}{*}{ Yes } & $167(11.4)$ & $39.2( \pm 10.7)$ & $43.4( \pm 11.4)$ \\
\hline & & t-test $(1465)=8.79, p<0.001$ & t-test $(1465)=1.71, p=0.086$ \\
\hline \multicolumn{4}{|c|}{ Musculoskeletal problem } \\
\hline No & $1303(88.8)$ & $47.2( \pm 10)$ & $45.4( \pm 11.4)$ \\
\hline \multirow[t]{2}{*}{ Yes } & $164(11.2)$ & $35.4( \pm 10.5)$ & $41.1( \pm 12.7)$ \\
\hline & & t-test $(1465)=14.17, p<0.001$ & t-test $(1465)=4.42, p<0.001$ \\
\hline \multicolumn{4}{|l|}{ Heart disease } \\
\hline No & $1352(92.2)$ & $46.6( \pm 10.6)$ & $45.1( \pm 11.6)$ \\
\hline \multirow[t]{2}{*}{ Yes } & $115(7.8)$ & $37.7( \pm 9.2)$ & $42.5( \pm 11.3)$ \\
\hline & & t-test $(1465)=8.75, p<0.001$ & t-test $(1465)=2.32, p=0.02$ \\
\hline
\end{tabular}


Table 1 SF-12 summary scores according to selected characteristics of the study population (Continued)

\begin{tabular}{|c|c|c|c|}
\hline \multicolumn{4}{|c|}{ Gastrointestinal illness } \\
\hline No & $1375(93.7)$ & $46.2( \pm 10.6)$ & $45.2( \pm 11.5)$ \\
\hline \multirow[t]{2}{*}{ Yes } & $92(6.3)$ & $40.3( \pm 11.2)$ & $39.7( \pm 11.9)$ \\
\hline & & t-test $(1465)=5.15, p<0.001$ & t-test $(1465)=4.48, p<0.001$ \\
\hline \multicolumn{4}{|c|}{ Asthma/COPD } \\
\hline No & $1390(94.7)$ & $46.3( \pm 10.6)$ & $44.9( \pm 11.6)$ \\
\hline \multirow[t]{2}{*}{ Yes } & $77(5.3)$ & $38.9( \pm 10.3)$ & $43.7( \pm 12.3)$ \\
\hline & & t-test $(1465)=5.91, p<0.001$ & t-test $(1465)=0.93, p=0.35$ \\
\hline \multicolumn{4}{|c|}{ Psychiatric disease } \\
\hline No & $1431(97.5)$ & $46( \pm 10.7)$ & $45.2( \pm 11.5)$ \\
\hline \multirow[t]{2}{*}{ Yes } & $36(2.5)$ & $41.9( \pm 10.7)$ & $32.7( \pm 9.9)$ \\
\hline & & t-test $(1465)=2.26, p=0.024$ & t-test $(1465)=6.44, p<0.001$ \\
\hline
\end{tabular}

differences of mean PCS-12 and MCS-12 according to various characteristics (demographics, presence of chronic diseases, behavioral risk factors, and utilization of health services). The two models were built since they allowed us to assess each of these differences independently of the other potential covariates. Therefore, modelling was only performed for adjustment of the differences and not for making predictions. All of the tests for significance were two sided and p-values $\leq 0.05$ were considered statistically significant. The data were analyzed using the Stata software program, version 11 [27].

A detailed display of the covariates included in the univariate and multivariate analysis is reported in Table 1 and Table 2.

\section{Results}

Selected characteristics of the sample are reported in Table 1. Among the eligible respondents, the mean age was 52.3 years (range 18-87), 38.8\% of respondents did not have any chronic disease, $32.6 \%$ had one, $18.4 \%$ had two and $10.2 \%$ had three or more chronic diseases. $33.7 \%$ of patients suffered from hypertension, $11.4 \%$ from diabetes, $11.2 \%$ from musculoskeletal problem, $7.8 \%$ from heart disease, $6.3 \%$ from chronic gastrointestinal illness and 5.3\% from Asthma/COPD. Psychiatric disorders were reported by $2.5 \%$ of respondents.

The SF-12 items and PCS-12 and MCS-12 summary scores are presented in Table $3.37 .3 \%$ of the sample evaluated their health in general as poor or fair, and most of the items showed negative perceptions in percentages generally approaching or exceeding $40 \%$ of the sample, except for negative emotions (21.1\%).

The overall mean PCS-12 was 45.9 (SD \pm 10.8 ; median $=48.9)$, whereas the overall mean MCS-12 was $44.9(\mathrm{SD} \pm 11.6$; median $=46.7)$.

Table 1 and Table 2 present the results of univariate and multivariate analysis. Univariate analysis highlighted significant differences by socio-demographic characteristics; indeed, PCS-12 and MCS-12 were significantly lower in females, elderly, unemployed and in less educated subjects. PCS-12 was significantly higher in the unmarried, but in contrast, was lower in subjects living alone. Also, MCS-12 was significantly higher in the excessive drinkers and PCS-12 in current smokers and excessive drinkers.

Worse PCS-12 and MCS-12 were reported by patients affected by at least one chronic disease, and the scores decreased with the increasing number of chronic diseases. Indeed, patients with three or more chronic diseases reported 17.4 and 7.8 points lower scores on PCS12 and MCS-12 compared to subjects without chronic illnesses, respectively.

Finally, both MCS-12 and PCS-12 were significantly lower in subjects having higher health services utilization, such as PCP and specialist visits, emergency accesses, hospital admissions, etc.

When the multivariate analysis was performed, the results did not substantially change, with the exception of excessive alcohol use and current smoking patients that showed a significantly lower PCS-12 and MCS-12 scores, respectively.

\section{Discussion}

The main result of our study is that it highlighted a poor perceived HRQOL of primary care patients in one of the poorest areas of Italy. Also, this study is one of the few that measured the HRQOL, analyzing both summary scores and SF-12 single items. The prevalence of subjects rating their health as unsatisfactory was one of the highest ever encountered in the literature [5,11,19,20,28-32], as well as at all SF-12-scales, particularly in Physical Functioning (PF), Emotional Role (ER), Bodily Pain (BP), and Social Functioning (SF). 


\begin{tabular}{|c|c|c|c|c|c|c|c|c|}
\hline & \multicolumn{4}{|c|}{ PCS-12 } & \multicolumn{4}{|c|}{ MCS-12 } \\
\hline & \multicolumn{4}{|c|}{$\begin{array}{l}F(19,1447)=53.81, p<0.001 \\
R 2=0.41, \text { Adjusted } R 2=0.41\end{array}$} & \multicolumn{4}{|c|}{$\begin{array}{l}\mathrm{F}(17,1449)=15.00, \mathrm{p}<0.001 \\
\mathrm{R} 2=0.15, \text { Adjusted } \mathrm{R} 2=0.14\end{array}$} \\
\hline & COEFF & SE & $t$ & P-value & COEFF & SE & $\mathrm{t}$ & P-value \\
\hline \multicolumn{9}{|l|}{ Socio-demographic profile } \\
\hline \multicolumn{9}{|l|}{ Gender, (male as reference) } \\
\hline Female & -1.50 & 0.47 & -3.20 & 0.001 & -4.58 & 0.59 & -7.75 & $<0.001$ \\
\hline Age, continuous & -0.14 & 0.02 & -7.63 & $<0.001$ & - & & & \\
\hline \multicolumn{9}{|l|}{ Marital status, (married as reference) } \\
\hline Unmarried/widowed/divorced/separated & -0.54 & 0.49 & -1.11 & 0.265 & - & & & \\
\hline Number in households, ordinal* & - & & & & -0.90 & 0.49 & -1.85 & 0.065 \\
\hline Education level, ordinal ${ }^{\circ}$ & 1.39 & 0.25 & 5.47 & $<0.001$ & 0.89 & 0.32 & 2.78 & 0.005 \\
\hline \multicolumn{9}{|l|}{ Working activity, (unemployed as reference) } \\
\hline Employed & - & & & & - & & & \\
\hline \multicolumn{9}{|l|}{ Behavioral risk factors } \\
\hline \multicolumn{9}{|l|}{ Smoking habit, (never smoker as reference) } \\
\hline Ex-smoker & -0.55 & 0.57 & -0.98 & 0.327 & - & & & \\
\hline Current smoker & 0.88 & 0.55 & 1.59 & 0.112 & -2.29 & 0.68 & -3.37 & 0.001 \\
\hline \multicolumn{9}{|l|}{ Alcohol abuse (non-excessive drinker as reference) } \\
\hline Excessive drinker & -1.65 & 0.83 & -2.00 & 0.045 & 1.63 & 1.07 & 1.53 & 0.127 \\
\hline \multicolumn{9}{|l|}{ Chronic diseases } \\
\hline Hypertension (absence as reference) & -0.54 & 0.56 & -0.97 & 0.333 & -1.89 & 0.70 & -2.70 & 0.007 \\
\hline Diabetes (absence as reference) & -1.87 & 0.73 & -2.56 & 0.011 & - & & & \\
\hline Musculoskeletal problem (absence as reference) & -6.96 & 0.73 & -9.47 & $<0.001$ & -1.48 & 0.94 & -1.58 & 0.115 \\
\hline Heart disease (absence as reference) & -2.93 & 0.87 & -3.37 & 0.001 & -1.51 & 1.10 & -2.70 & 0.173 \\
\hline Gastrointestinal illness (absence as reference) & -2.02 & 0.91 & -2.22 & 0.026 & -3.71 & 1.17 & -3.15 & 0.002 \\
\hline Asthma/COPD (absence as reference) & -4.66 & 0.98 & -4.74 & $<0.001$ & - & & & \\
\hline Psychiatric disorders (absence as reference) & - & & & & -10.11 & 1.84 & -5.49 & $<0.001$ \\
\hline \multicolumn{9}{|c|}{ Utilization of health services during the previous year } \\
\hline \multicolumn{9}{|l|}{$P C P^{\S}$ accesses, $(<1$ time per month as reference) } \\
\hline$\geq 1$ time per month & -1.34 & 0.56 & -2.40 & 0.017 & -1.65 & 0.72 & -2.31 & 0.021 \\
\hline $\mathrm{PCP}^{\S}$ medical visits, ordinal ${ }^{\dagger}$ & -1.67 & 0.34 & -4.87 & $<0.001$ & -0.86 & 0.44 & -1.95 & 0.051 \\
\hline \multicolumn{9}{|c|}{ Specialist visits in community health services, ( $<1$ time as reference) } \\
\hline$\geq 1$ & -2.33 & 0.47 & -4.99 & $<0.001$ & -1.45 & 0.61 & -2.39 & 0.017 \\
\hline \multicolumn{9}{|l|}{ Private specialist visits, (<1 time as reference) } \\
\hline$\geq 1$ & -0.46 & 0.44 & -1.04 & 0.300 & -1.62 & 0.58 & -2.81 & 0.005 \\
\hline \multicolumn{9}{|l|}{ Emergency accesses, ( $<1$ time as reference) } \\
\hline$\geq 1$ & -1.18 & 0.55 & -2.15 & 0.032 & -1.06 & 0.71 & -1.51 & 0.132 \\
\hline \multicolumn{9}{|l|}{ Hospital admissions, ( $<1$ time as reference) } \\
\hline$\geq 1$ & -3.10 & 0.69 & -4.53 & $<0.001$ & -1.51 & 0.89 & -1.70 & 0.090 \\
\hline
\end{tabular}

* Number in households: (none $=0,1=1,>1=2){ }^{\circ}$ Education level: (no formal education $=1$, primary school $=2$, secondary school $=3$, high school or higher $=4$ ); ${ }^{\S} \mathrm{PCP}=$ primary care physician; ${ }^{\dagger} \mathrm{PCP}$ medical visits in the previous year: (none $=0,<1$ time per month $=1, \geq 1$ time per month $=2$ ).

Consistent with national ISTAT data [33], revealing that subjects living in the South presented a poorer selfperceived health status, we found that PCS-12 and MCS12 were lower than Italian general population norms (mean PCS-12 $=50.4$, mean MCS-12 $=49.8$ ). Moreover, the comparisons with results reported by similar surveys show that our observed mean scores are generally considered substantially lower than those expected $[5,16,29]$. 
Table 3 SF-12 items and summary scores

\begin{tabular}{|c|c|c|c|c|c|c|}
\hline \multirow[t]{2}{*}{ Item description* (Health domain) } & \multicolumn{6}{|c|}{ Item response category frequencies (\%) } \\
\hline & Excellent & Very good & Good & Fair & Poor & \\
\hline \multirow[t]{2}{*}{ 1. General health perception $\left(\mathrm{GH}^{\circ}\right)$} & 6.5 & 16.6 & 39.6 & 27.3 & 10 & \\
\hline & Yes, a lot & Yes, a little & Not limited & & & \\
\hline $\begin{array}{l}\text { 2. Limitations in moderate activities during a typical } \\
\text { day }\left(\mathrm{PF}^{\Phi}\right)\end{array}$ & 11.2 & 26.4 & 62.4 & & & \\
\hline \multirow{2}{*}{$\begin{array}{l}\text { 3. Limitations in climbing several flights of stairs during } \\
\text { a typical day }\left(\mathrm{PF}^{\S}\right)\end{array}$} & 11.6 & 26.2 & 62.2 & & & \\
\hline & Yes & No & & & & \\
\hline 4. Because accomplishment less of physical health $\left(\mathrm{PR}^{\dagger}\right)$ & 37.3 & 62.7 & & & & \\
\hline 5. Limitation in work because of physical health $\left(\mathrm{PR}^{\dagger}\right)$ & 35 & 65 & & & & \\
\hline $\begin{array}{l}\text { 6. Because accomplishment less of emotional } \\
\text { problems }\left(\mathrm{ER}^{\ddagger}\right)\end{array}$ & 42.9 & 57.1 & & & & \\
\hline \multirow[t]{2}{*}{ 7. Because carefulness less of emotional problems (ER $\left.{ }^{\ddagger}\right)$} & 40 & 60 & & & & \\
\hline & Not at all & A little bit & Moderately & Quite a bit & Extremely & \\
\hline \multirow{2}{*}{$\begin{array}{l}\text { 8. Interference of bodily pain with normal } \\
\text { activities }\left(\mathrm{BP}^{* *}\right)\end{array}$} & 38.5 & 16.5 & 27.6 & 15 & 2.4 & \\
\hline & $\begin{array}{l}\text { All of the } \\
\text { time }\end{array}$ & $\begin{array}{l}\text { Most of the } \\
\text { time }\end{array}$ & $\begin{array}{l}\text { A good bit of } \\
\text { the time }\end{array}$ & $\begin{array}{l}\text { Some of the } \\
\text { time }\end{array}$ & $\begin{array}{l}\text { A little of the } \\
\text { time }\end{array}$ & $\begin{array}{l}\text { None of the } \\
\text { time }\end{array}$ \\
\hline 9. Calm and peaceful $\left(\mathrm{MH}^{\circ 0}\right)$ & 11.7 & 26.8 & 13.7 & 29.9 & 13.5 & 4.4 \\
\hline 10. Lot of Energy $\left(V^{\S \S}\right)$ & 15.3 & 23.9 & 15 & 29.3 & 13.1 & 3.4 \\
\hline 11. Downhearted and blue $\left(\mathrm{MH}^{\circ \circ}\right)$ & 4.3 & 9.1 & 7.7 & 30 & 30.1 & 18.8 \\
\hline $\begin{array}{l}\text { 12. Interference of physical or emotional problems with } \\
\text { social activities }\left(\mathrm{SF}^{+\dagger}\right)\end{array}$ & 1.8 & 7.7 & - & 26 & 25.7 & 38.8 \\
\hline Summary scores & Median & Mean $( \pm S D)$ & & & & \\
\hline Physical Component Summary (PCS) & 48.9 & $45.9( \pm 10.8)$ & & & & \\
\hline Mental Component Summary (MCS) & 46.7 & $44.9( \pm 11.6)$ & & & & \\
\hline
\end{tabular}

${ }^{*}$ Items 4-12 investigate health conditions during the previous 4 weeks ; ${ }^{\circ} G H=$ General Health; ${ }^{\S} P F=$ Physical Functioning; ${ }^{\dagger} P R=$ Physical Role; ${ }^{\ddagger} E R=$ Emotional Role; ${ }^{* *} \mathrm{BP}=$ Bodily Pain; ${ }^{\circ} \mathrm{MH}=$ Mental Health; ${ }^{\S \S} \mathrm{V}=$ Vitality; ${ }^{\dagger+} \mathrm{SF}=$ Social Functioning.

The reasons for the observed perceived results are complex and may be attributable to several factors. A possible reason may be cultural differences in values and reference levels, rather than true differences in health status [34]. However, as shown in previous research, objective differences in HRQOL across countries were frequently observed, and political and welfare variables have been associated to these differences, since countries with stronger social welfare orientations seem to impact positively on quality of life, while a poorer HRQOL was frequently observed in people living in Southern regions $[35,36]$. Likewise, it seems reasonable to hypothesize that in Italy the marked Northern-Southern divide, not only in economic development, but also in the distribution of public welfare resources [37], can have a possible role on HRQOL, although the assessment of this relation was not an aim of this survey.

In line with previous studies [8,9,14-20,30-32,35,38-41], our findings showed significant differences in HRQOL by socio-demographic characteristics and behavioral risk factors, with both lower scores reported by females, less educated patients, current smokers and excessive alcohol drinkers, whereas only lower PCS-12 was reported by older patients and only lower MCS- 12 by separated or divorced patients.

As expected and according to other studies [5,11], we found that patient with chronic diseases reported significantly lower HRQOL and the decrements were larger in PCS-12 than in MCS-12. Patients with musculoskeletal problems and asthma/COPD showed lower PCS-12, while patients with hypertension and psychiatric disorders reported worse MCS-12. However, some of the observed results might reflect the combined influence of comorbid conditions, since a substantial percentage (28.6\%) of primary care patients suffers from more than one chronic condition. Indeed, HRQOL was strongly poorer in patients affected by multimorbidities.

Poorer HRQOL was reported by patients with higher health services utilization, and this result is consistent with previous research [5,42]. Although it is well-known that health services utilization is related to many factors, such as patients' preferences, awareness of their medical 
profile, availability of services and their expectations [42], and although our study was not designed to investigate utilization of health services according to HRQOL, it should be pointed out that our results seem to hypothesize that HRQOL may be used as a valuable tool for the estimation of health services needs $[43,44]$. In support to the potentials of the SF-12 in health services research, it may be mentioned the estimation of a preference measure of health derived from the SF-12 that has been proposed by Brazier and Roberts for the assessment of cost-effectiveness of health care intervention [45].

Our findings must be interpreted in the context of study's limitations. First, as most research on this topic $[5,8,11,14-20,28,29,31,32]$, our survey was performed as cross-sectional and it is well known that cross-sectional design does not allow any cause-effect relationship and poses many problems in relation to hypothesis testing since data on "risk factors" and "outcomes" are assessed at the same time. However, it was not our aim to draw conclusions on predictive relationships. Nonetheless, this study represents a useful way to determine the prevalence of poor HRQOL and, eventually, to identify HRQOL differences among subgroups disaggregated by demographics, presence of chronic diseases, behavioral risk factors, and utilization of health services, in order to target preventive interventions on those subjects that manifest poorer HRQOL. Second, data were based entirely on patients self-reporting; however, we do not think that method of data collection may represent a problem because self-reporting is the only way to collect subjective information about various domains of perceived health status. Third, as is the case of all questionnaire surveys, another limitation is the potential recall bias, especially in the elderly. However, recall bias was mitigated by having restricted recall within a specified period; in addition, the prevalence of elderly people in our study $(29.2 \%$ aged $\geq 65$ years and $3.1 \%$ aged $\geq$ 80 years) was similar or lower than in previous research on HRQOL $[10,12,15,16,18,28,31,34]$, and the SF-12, being oriented more to perceptions rather than on objective health events, is particularly suited to the elderly.

\section{Conclusions}

Our findings seem to indicate that primary care patients in Southern Italy have a poor HRQOL and this perception is even poorer in subgroups of the population, according to several sociodemographic, clinical characteristics, and behavioural risk factors. These results may have significant implications for health care policymakers, since they emphasize the need of developing effective and targeted strategies to improve HRQOL in Southern Italy, and provide support to monitor this process using the SF-12, that may be easily incorporated into the systematic evaluation of the patients in primary care settings. Further research is needed to replicate and validate these results on potential determinants of HRQOL through longitudinal studies, and to confirm the hypothesis that HRQOL may be used for the estimation of health services needs.

\section{Abbreviations}

HRQOL: Health related quality of life; SF-12: Short-form-12 health survey; PCS-12: Physical component summary; MCS-12: Mental component summary; PCP: Primary care physician; GH: General health; PF: Physical functioning; PR: Physical role; ER: Emotional role; BP: Bodily Pain; MH: Mental health; V: Vitality; SF: Social functioning.

\section{Competing interests}

The authors declare that they have no competing interests.

\section{Authors' contributions}

BM collected the data, and contributed to the data analysis and interpretation and wrote the first draft of the article. PR, CP and $A B$ contributed to conception and design of the study, collected the data, and contributed to the data analysis and interpretation. MP designed the study, was responsible for the data analysis and interpretation, have been involved in revising the manuscript and have given final approval of the version to be published. All authors read and approved the final manuscript.

\section{Acknowledgements}

The authors wish to thank all of the men and women who agreed to participate in this study.

Received: 26 October 2012 Accepted: 29 May 2013

Published: 10 June 2013

\section{References}

1. The WHOQOL Group: The World Health Organization quality of life assessment (WHOQOL): position paper from the World Health Organization. Soc Sci Med 1995, 41:1403-1409.

2. Ware J Jr, Kosinski M, Keller SD: A 12-Item Short-Form Health Survey: construction of scales and preliminary tests of reliability and validity. Med Care 1996, 34:220-233.

3. Hays RD, Morales LS: The RAND-36 measure of health-related quality of life. Ann Med 2001, 33:350-357

4. Jenkinson C, Layte R: Development and testing of the UK SF-12 (short form health survey). J Health Serv Res Policy 1997, 2:14-18.

5. Kontodimopoulos N, Pappa E, Niakas D, Tountas Y: Validity of SF-12 summary scores in a Greek general population. Health Qual Life Outcomes 2007, 5:55-63.

6. Gandek B, Ware JE, Aaronson NK, Apolone G, Bjorner JB, Brazier JE, Bullinger M, Kaasa S, Leplege A, Prieto L, Sullivan M: Cross-validation of item selection and scoring for the SF-12 Health Survey in nine countries: results from the IQOLA Project. International Quality of Life Assessment. J Clin Epidemiol 1998, 51:1171-1178.

7. Kodraliu G, Mosconi P, Groth N, Carmosino G, Perilli A, Gianicolo EA, Rossi C, Apolone G: Subjective health status assessment: evaluation of the Italian version of the SF-12 Health Survey. Results from the MiOS Project. J Epidemiol Biostat 2001, 6:305-316.

8. Guerra CE, Shea JA: Health literacy and perceived health status in Latinos and African Americans. Ethn Dis 2007, 17:305-312.

9. Hanmer J, Lawrence WF, Anderson JP, Kaplan RM, Fryback DG: Report of nationally representative values for the no institutionalized US adult population for 7 health-related quality-of-life scores. Med Decis Making 2006, 26:391-400.

10. Jakobsson U: Using the 12-item Short Form health survey (SF-12) to measure quality of life among older people. Aging Clin Exp Res 2007, 19:457-464.

11. Wee CC, Davis RB, Hamel MB: Comparing the SF-12 and SF-36 health status questionnaires in patients with and without obesity. Health Qual Life Outcomes 2008, 6:11-17.

12. Côté I, Grégoire JP, Moisan J, Chabot I: Quality of life in hypertension: the SF-12 compared to the SF-36. Can J Clin Pharmacol 2004, 11:e232-e238. 
13. Pezzilli $R$, Morselli-Labate AM, Fantini L, Campana D, Corinaldesi $R$ : Assessment of the quality of life in chronic pancreatitis using Sf-12 and EORTC Qlq-C30 questionnaires. Dig Liver Dis 2007, 39:1077-1086.

14. Tang LY, Nabalamba A, Graff LA, Bernstein CN: A comparison of selfperceived health status in inflammatory bowel disease and irritable bowel syndrome patients from a Canadian national population survey. Can J Gastroenterol 2008, 22:475-483.

15. Wolf MS, Gazmararian JA, Baker DW: Health literacy and functional health status among older adults. Arch Intern Med 2005, 165:1946-1952.

16. Sorkin D, Tan AL, Hays RD, Mangione CM, Ngo-Metzger Q: Self-reported health status of vietnamese and non-Hispanic white older adults in California. J Am Geriatr Soc 2008, 56:1543-1548.

17. Wang R, Wu C, Zhao Y, Yan X, Ma X, Wu M, Liu W, Gu Z, Zhao J, He J: Health related quality of life measured by SF-36: a population-based study in Shanghai, China. BMC Public Health 2008, 8:292-299.

18. de Belvis AG, Avolio M, Sicuro L, Rosano A, Latini E, Damiani G, Ricciardi W: Social relationships and HRQL: a cross-sectional survey among older Italian adults. BMC Public Health 2008, 8:348-357.

19. Caputo RK: The effects of socioeconomic status, perceived discrimination and mastery on health status in a youth cohort. Soc Work Health Care 2003, 37:17-42.

20. Overland S, Glozier N, Maeland JG, Aarø LE, Mykletun A: Employment status and perceived health in the Hordaland Health Study (HUSK). BMC Public Health 2006, 6:219-227.

21. Apolone G, Mosconi P, Quattrociocchi L, Gianicolo EAL, Groth N, Ware JE: Questionario sullo stato di salute Sf-12, Versione Italiana.; 2005. http://crc marionegri.it/qdv/downloads/SF12\%20Manuale.pdf.

22. Ware JE, Kosinski M, Keller SD: How to score the SF-12 physical and mental health summary scales 2nd edition. Boston, MA: The Health Institute; 1995.

23. The World Health Organization: Health topics: chronic diseases. http://www. who.int/topics/chronic_diseases/en/.

24. Centers for Disease Control and Prevention (CDC), Department of Health and Human Services: Behavioral Risk Factor Surveillance System Survey Questionnaire;; 2007. http://www.cdc.gov/brfss/questionnaires/pdf-ques/ 2007brfss.pdf.

25. Istituto Superiore di Sanità. Centro Nazionale di Epidemiologia, Sorveglianza e Promozione della Salute: Studio Progressi delle Aziende Sanitarie per la Salute in Italia (PASSI). http://www.epicentro.iss.it/passi/pdf/QES_Passi.pdf.

26. International Center for Alcohol Policies: International Drinking Guidelines. ICAP.; 2003. http://www.icap.org/portals/0/download/all_pdfs/ ICAP_Reports_English/report14.pdf.

27. Stata Corporation: Stata Statistical Software: Release 11. College Station, TX: StataCorp LP; 2009.

28. Larson CO, Schlundt D, Patel K, Beard K, Hargreaves M: Validity of the SF-12 for use in a low-income African American community-based research initiative (REACH 2010). Prev Chronic Dis 2008, 5:A44-A57.

29. Montazeri A, Vahdaninia M, Mousavi SJ, Omidvari S: The Iranian version of 12-item Short Form Health Survey (SF-12): factor structure, internal consistency and construct validity. BMC Public Health 2009, 9:341-350.

30. Windsor TD, Rodgers B, Butterworth P, Anstey KJ, Jorm A: Measuring physical and mental health using the SF-12: implications for community surveys of mental health. Aust N Z J Psychiatry 2006, 40:797-803.

31. Savoia E, Fantini MP, Pandolfi PP, Dallolio L, Collina N: Assessing the construct validity of the Italian version of the EQ-5D: preliminary results from a cross-sectional study in North Italy. Health Qual Life Outcomes 2006, 4:47-55

32. McFadden $E$, Luben $R$, Bingham $S$, Wareham $N$, Kinmonth AL, Khaw KT: Social inequalities in self-rated health by age: Cross-sectional study of 22 457 middle-aged men and women. BMC Public Health 2008, 8:230-237

33. Istituto Nazionale di Statistica (ISTAT: Condizioni di salute, fattori di rischio e ricorso ai servizi sanitari. Anno:; 2005. http://www.istat.it/salastampa/ comunicati/non_calendario/20070302 00/testointegrale.pdf.

34. Jurges $\mathrm{H}$ : True health vs. response styles: exploring cross-country differences in self-reported health. Health Econ 2007, 16:163-178.

35. Espelt A, Borrell C, Rodríguez-Sanz M, Muntaner C, Pasarín Ml, Benach J, Schaap $M$, Kunst AE, Navarro $V$ : Inequalities in health by social class dimensions in European countries of different political traditions. Int $J$ Epidemiol 2008, 37:1095-1105.

36. Eikemo TA, Huisman M, Bambra C, Kunst A: Health inequalities according to educational level in different welfare regimes: a comparison of 23 European countries. Sociol Health IIIn 2008, 30:565-582.
37. The European Observatory on Health Care Systems: Health Care Systems in Transition. Italy. http://www.euro.who.int/_data/assets/pdf_file/0009/85455/ E73096.pdf.

38. Welin C, Wilhelmsen L, Welin L, Johansson S, Rosengren A: Perceived health in 50-year-old women and men and the correlation with risk factors, diseases, and symptoms. Gend Med 2011, 8:139-149.

39. Nolte $E$, McKee M: Changing health inequalities in East and West Germany since unification. Soc Sci Med 2004, 58:119-136.

40. Croghan IT, Schroeder DR, Hays JT, Eberman KM, Patten CA, Berg EJ, Hurt RD: Nicotine dependence treatment: perceived health status improvement with 1-year continuous smoking abstinence. Eur J Public Health 2005, 15:251-255.

41. Hung DY, Lubetkin El, Fahs MC, Shelley DR: Assessing the impact of behavioral risk factors and known-groups validity of the SF-12 in a US Chinese immigrant population. Med Care 2009, 47:262-267.

42. Pappa E, Niakas D: Assessment of health care needs and utilization in a mixed public-private system: the case of the Athens area. BMC Health Serv Res 2006, 6:146-156.

43. Jayasinghe UW, Proudfoot J, Barton CA, Amoroso C, Holton C, Davies GP Beilby J, Harris MF: Quality of life of Australian chronically-ill adults: patient and practice characteristics matter. Health Qual Life Outcomes 2009, 7:50

44. Lam CL, Fong DY, Lauder IJ, Lam TP: The effect of health-related quality of life (HRQOL) on health service utilisation of a Chinese population. Soc Sci Med 2002, 55:1635-1646.

45. Brazier J, Roberts J: The estimation of a preference-based measure of health from the SF-12. Med Care 2004, 42:851-859.

doi:10.1186/1477-7525-11-93

Cite this article as: Manuti et al: Assessment of perceived health status among primary care patients in Southern Italy: findings from a crosssectional survey. Health and Quality of Life Outcomes 2013 11:93.

\section{Submit your next manuscript to BioMed Central and take full advantage of:}

- Convenient online submission

- Thorough peer review

- No space constraints or color figure charges

- Immediate publication on acceptance

- Inclusion in PubMed, CAS, Scopus and Google Scholar

- Research which is freely available for redistribution 